\title{
The Effect of Population Socio-Economic Characteristics on Tourism Demand in Serbia: A Survey
}

\author{
Slavoljub Vujović ${ }^{1}$, Nenad Vujić2 ${ }^{2}$ Zoran Jovnovic ${ }^{3}$, Petar Vuković ${ }^{4}$ \\ ${ }^{1} \mathrm{PhD}$, Senior Research Associate, BBS, Belgrade, Serbia \\ ${ }^{2} \mathrm{PhD}$, Research Associate, Economics Institute, Belgrade, Serbia \\ ${ }^{3}$ MA, Professor, Technical School, Novi Beograd, Serbia \\ ${ }^{4} \mathrm{PhD}$ Student, Assembly of Serbia, Belgrade, Serbia \\ Correspondence: Slavoljub Vujović, PhD, Senior Research Associate, BBS, Belgrade, Serbia. \\ E-mail: kelovic1967@yahoo.com \\ Received: December 29, 2016 \\ Accepted: January 14, 2017 \\ Online Published: February 22, 2017 \\ doi:10.5539/ibr.v10n3p232 \\ URL: https://doi.org/10.5539/ibr.v10n3p232
}

\begin{abstract}
The synthesis of various theoretical concepts and empirical research confirms the significance of leisure time and leisure funds as fundamental factors of tourism demand. It also confirms the fact that the correlation between resources and needs shows that all the person's efforts are directed to coordination between their needs and means and that those tourist needs are manifested through the tourist consumption. Therefore, the study is based on the assumption that socio-economic characteristics of population have a great influence on the decision concerning where and how the vacation will be used.

Thus, the aim of the research was to determine whether there is and how important is the influence of socio-economic characteristics of the population as independent variables on the scope and direction of movement of tourist demand in the particular case in practice.

Based on the conducted research and analysed results, the authors strived to examine the initial hypotheses, that is to provide a statistical correlation between the dependent and independent variables.

The results of research confirm the hypothesis that the socio-economic characteristics of working and living conditions of the population have a great impact on the dynamics and scope of tourism demand.

According to the defined aim, the theoretical elaboration of the results dominates the study. During the research and results analysis, the following methods were used: T-test, One-Factor Analysis of Variance, Pearson Correlation Coefficient, Logistic Regression and Multiple Regression.
\end{abstract}

Keywords: tourism, development, socio-economic characteristics of population, tourist demand

JEL: A12, A13, Z32

\section{Introduction}

In this study, it has been examined if the attitudes of the Serbian respondents and their habits concerning their vacations can be connected to some of their socio-economic characteristics. Specifically, we were curious to know if these behavioural segments were connected with the number of the household members, the number of the members with income and the employment status of the respondents, their perception and habits as to how important certain elements of their vacation accommodation are, as well as their attitudes toward certain events and tourism in Serbia in general. Research is done with student of doctoral studies of state university in Kragujevac city, the time of school in 2015 and 2016 years.

Serbia as a country that has natural conditions for developing tourism in mountains and spas, for the development of congress tourism, and has seven million people with the prospect of imminent accession to the European Union, taken as an example, which should present the situation in other countries of the Balkan Peninsula and the entire South East Europe.

The hypothesis is that the socio-economic characteristics of the population over the impact on tourism demand determine the dynamics and scope of tourism development. 
Namely, our assumption is that these everyday aspects of average citizens of Serbia, to a significant extent, influence their choices concerning their vacation; therefore, we believe that is necessary to examine the connection between these variables in order to better understand the citizens' habits and attitudes which are related to vacation trends and tourism in Serbia in general.

This study included 183 respondents, of whom 78 respondents (42.6\%) were male, and 105 respondents (57.4\%) were female. When it comes to their age, the respondents were divided into following categories: $6.6 \%$ of the respondents were $20-30$ years of age, $41 \%$ were $31-40$, the same percentage were $41-50$ years of age, $3.3 \%$ were 51-65 and $8.2 \%$ were above 65 . Then, the employment status of the respondents was examined $-77 \%$ of the respondents were employed, $14.8 \%$ were unemployed, $1.6 \%$ were pupils or students and $6.6 \%$ were retired.

When it comes to education, $41 \%$ of the respondents had high school degrees, $44.3 \%$ had college degrees, $14.8 \%$ had master's degrees or doctorate degrees.

Furthermore, when it comes to their monthly incomes, the respondents were divided into following categories: $11.5 \%$ of the respondents stated they did not have any personal income, $47.5 \%$ had up to 500 euros of income, $27.9 \%$ made 501-1000 euros on monthly basis, $9.8 \%$ made 1001-1500 euros, no respondent made 1501-2000 euros and $3.3 \%$ of the respondents stated they made more than 2000 euros every month. In addition to their personal income, the respondents were divided into certain categories according to the monthly income of the household they live in. No respondent stated they were not familiar with the income of their household. $19.7 \%$ of the respondents lived in households with monthly income up to 500 euros, $54.1 \%$ lived in households with 501-1000 euros of monthly income, $9.8 \%$ were in the category with 1001-1500 euros of monthly income, $4.9 \%$ were in 1501-2000 euro category, the same percentage of the respondents were in the 2001-3000 euro category, $3.3 \%$ lived in a household with more than 3000 euros of monthly income, and the same percentage of the respondents stated that they were not familiar with the information.

Furthermore, when it comes to the type of the household: $9.8 \%$ of the respondents lived alone, $23 \%$ lived in two-member households, $24.6 \%$ in three-member households, $34.4 \%$ in four-member households, $4.9 \%$ in five-member households, $3.3 \%$ in six-member households, and no one stated they lived in household of seven members or more. When it comes to the division of the respondents according to how many members of the household earned income, it is shown that $29.5 \%$ of the respondents lived in households with only one income, $59 \%$ lived in households with two incomes, $9.8 \%$ lived in households with three incomes, $1.6 \%$ in households with four incomes, and no one stated they lived in households with more than four incomes.

The main objective of this study is to examine to what extent and in which way the socioeconomics variables (i.e. the number of household members, the number of the members generating income, the respondents' age, their employment status, their habits and attitudes) reflect the tourist events and tourism in Serbia, i.e. how the respondents spend their vacation in one of the tourist destinations in Serbia.

\section{Methodology}

This study is quantitative in nature, it was conducted via on line survey, and the obtained data were analysed through Statistical Package for the Social Sciences (SPSS) 17.0 version. Besides the socio-demographic variables (Muratovic, 2013), the survey contained multiple choice questions about the habits concerning the way respondents spend their vacation (Bulent, \& others 2015), so they chose the answer that best reflected their habits (Vujovic, 2008).

The second group of dependent variables (Petrovecki \& Bili-Zule, 2015) was operationalized through five-degree Likert Scale (Butrovac, 2014), a type of assessment within which the respondent themselves assessed the importance of certain elements of their vacation accommodation to them.

The third and the fourth group of dependent variables were also operationalized through five-degree Likert Scale within which the respondents stated the degree of their interest in certain attractions/events in our country as well as their agreement with assertions about our country's tourism in general. The importance of socio-economic characteristics of the population for different cycles of the company researched and explained J. L. Moreno in the book "Who Shall Survive?"(Moreno, 1978).

There were three independent variables in this study: the respondents employment status, the size of the households the respondents live in and the number of the household members who earn income.

When it comes to the first independent variable, the respondents' employment status, $77 \%$ respondents were employed, 14.8 were unemployed, $1.6 \%$ were pupils or students and $6.6 \%$ were retired. When it comes to the size of the households the respondents live in, $9.8 \%$ of the respondents lived alone, $23 \%$ lived in two-member households, $24.6 \%$ in three-member households, $34.4 \%$ in four-member households, $4.9 \%$ in five-member 
households, $3.3 \%$ in six-member households.

The last independent variable in this study shows the number of the household members who earn income $-29.5 \%$ of the respondents lived in households with only one income, $59 \%$ lived in households with two incomes, $9.8 \%$ lived in households with three incomes, $1.6 \%$ in households with four incomes.

Dependent variables were used to examine the respondents' habits concerning their way of spending their vacation, then to assess how important certain elements of vacation accommodation are, as well as the degree of their interest in certain attractions/events in our country and tourism in general.

Thus, through the first dependent variable, the respondents were asked how much money they were willing to set aside for their vacation, and $39.3 \%$ were ready to set aside one monthly income for it, $32.8 \%$ two monthly incomes, $3.3 \%$ were ready to spend three, nobody was ready to spend four monthly incomes, $8.2 \%$ were ready to set aside more than 4 monthly incomes and $16.4 \%$ of the respondents stated 'none of the above'.

The next dependent variable shows the way the respondents finance their vacation- $62.3 \%$ of the respondents finance it on their own, $13.1 \%$ finance it with the help of the parents, children, family or partner, $3.3 \%$ finance it by getting a bank loan, $14.8 \%$ of the respondents use deferred payment, as $6.6 \%$ of the respondents finance their vacation in some other way.

Then, it was also examined in which way the respondents like to spend their vacation, so it was ascertained that the biggest number of respondents, $75.4 \%$, spend their vacation at the seaside, $6.6 \%$ like the mountains, no one stated that they loved to spend their vacation at a lake, $1.6 \%$ of the respondents like to spend their vacation at a spa resort, $3.3 \%$ would choose farm tourism, $4.9 \%$ would choose city tourism (in their country or in a foreign country), and $8.2 \%$ stated they spend their vacation in other ways.

Further on, it was examined which country the respondents like to spend their vacation in, so $62.3 \%$ stated that Greece was the country they would most likely to choose for their vacation, $8.2 \%$ stated Montenegro as a country where they like to spend their vacation, $1.6 \%$ stated that Turkey was their country of choice, $3.3 \%$ of the respondents would rather choose Egypt, only $1.6 \%$ chose Spain, as well as Croatia, $4.9 \%$ chose our country, $16.4 \%$ of the respondents stated that they would choose some other country (Grozeva, 2016).

The next variable was used to examine the respondents' preferences as to how long they like their vacation to be and in which periods they like to spend it - $1.6 \%$ stated they liked 7-day periods, $42.6 \%$ liked 10 -day periods, $14.8 \%$ chose 15 -day periods, $41 \%$ stated they liked a period of their own choosing.

Table 1. Elements of accommodation facility in percentages

\begin{tabular}{|c|c|c|c|c|c|}
\hline & 1 & 2 & 3 & 4 & 5 \\
\hline Mini bar & 62.3 & 18 & 3.3 & 14.8 & 1.6 \\
\hline Safe (in the room or at the Reception desk) & 27.9 & 16.4 & 9.8 & 29.5 & 16.4 \\
\hline Car Park & 11.5 & 4.9 & 4.9 & 32.8 & 45.9 \\
\hline Pool & 26.2 & 21.3 & 13.1 & 27.9 & 11.5 \\
\hline Aqua Park & 50.8 & 26.2 & 8.2 & 9.8 & 4.9 \\
\hline Sports Facilities & 36.1 & 19.7 & 14.8 & 26.2 & 3.3 \\
\hline Medical Service & 11.5 & 3.3 & 9.8 & 44.3 & 31.1 \\
\hline Spa & 42.6 & 24.6 & 9.8 & 11.5 & 11.5 \\
\hline Playground & 29.5 & 4.9 & 14.8 & 31.1 & 19.7 \\
\hline Kitchen/Kitchenette & 11.5 & 9.8 & 9.8 & 42.6 & 26.2 \\
\hline Flat Screen TV & 49.2 & 18 & 9.8 & 16.4 & 6.6 \\
\hline Jacuzzi & 57.4 & 24.6 & 3.3 & 9.8 & 4.9 \\
\hline Air-Conditioning & 9.8 & l & 8.2 & 42.6 & 39.3 \\
\hline $\begin{array}{l}\text { View of Tourist Attractions (beach, ski } \\
\text { slope...) }\end{array}$ & 18 & 8.2 & 13.1 & 42.6 & 18,0 \\
\hline Terrace & 3.3 & 1.6 & 4.9 & 37.7 & 52.5 \\
\hline Washing Machine & 49.2 & 24.6 & 11.5 & 9.8 & 4.9 \\
\hline Sound Insulation & 14.8 & 16.4 & 6.6 & 37.7 & 24.6 \\
\hline Wi-Fi & 6.6 & 9.8 & 9.8 & 27.9 & 45.9 \\
\hline Fitness Centre & 49.2 & 18 & 13.1 & 14.8 & 4.9 \\
\hline Non Smoking Rooms & 42.6 & 6.6 & 11.5 & 21.3 & 18,0 \\
\hline Family Rooms & 24.6 & 8.2 & 24.6 & 23,0 & 19.7 \\
\hline Pets Allowed & 54.1 & 4.9 & 18,0 & 14.8 & 8.2 \\
\hline Adapted for Persons with Disabilities & 32.8 & 3.3 & 27.9 & 16.4 & 19.7 \\
\hline Club/Disco for Children & 42.6 & 11.5 & 18,0 & 21.3 & 6.6 \\
\hline Services (Hairdresser, Masseur...) & 39.3 & 16.4 & 16.4 & 18,0 & 9.8 \\
\hline $\begin{array}{l}\text { Distance from the Tourist Attractions (Beach, } \\
\text { City Centre...) }\end{array}$ & 1.6 & 3.3 & 6.6 & 37.7 & 50.8 \\
\hline
\end{tabular}

Source: Research authors 
Also, we examined which means of transportation our respondents use - $68.9 \%$ stated they used their own transportation, $18 \%$ stated they travelled by bus, $1.6 \%$ chose train, none chose to travel by boat, and $11.5 \%$ of the respondents said they travelled by plane.

When it comes to accommodation, $16.4 \%$ of the respondents chose to stay in a hotel room, $11.5 \%$ chose a studio apartment or hotel accommodation, $4.9 \%$ chose a room in private accommodation, $41 \%$ chose an apartment or a studio apartment in private accommodation. Furthermore, $13.1 \%$ of the respondent chose the all inclusive option, $1.6 \%$ chose the camp site option, and 11.5 of the respondents stated they would choose some other means of accommodation.

Then, using the five degree Likert Scale, the respondents assessed to what extent they valued certain elements of accommodation when they plan their vacation. Table 1 shows the elements and frequencies of the respondents' responses, where 1 stood for 'irrelevant', and 5 stood for 'extremely relevant', other numbers represented nuances and 3 stood for 'not sure'.

In the next group of dependent variables, the respondents were required to give their assessments as to their interest in the domestic tourist attractions and events, using the five-degree Likert Scale, and the frequencies of the responses are shown in the Table 2 .

Table 2. Commitment of tourist to domestic touristics facilities in percentages

\begin{tabular}{|c|c|c|c|c|c|}
\hline & $\begin{array}{l}\text { Not } \\
\text { interested }\end{array}$ & Faintly interested & Not sure & Interested & $\begin{array}{l}\text { Broadly } \\
\text { interested }\end{array}$ \\
\hline Mountains & 36.1 & 21.3 & 9.8 & 21,3 & 11.5 \\
\hline Lakes & 26.1 & 24.6 & 16.4 & 14.8 & 8.2 \\
\hline Spa Resorts & 45.9 & 21.3 & 13.1 & 16.4 & 3.3 \\
\hline Congress Tourism & 63.9 & 16.4 & 6.6 & 9.8 & 3.3 \\
\hline Farm Tourism & 47.5 & 14.8 & 11.5 & 19.7 & 6.6 \\
\hline $\begin{array}{l}\text { The Guča Trumpet } \\
\text { Festival }\end{array}$ & 80.3 & 9.8 & 3.3 & 4.9 & 1.6 \\
\hline Exit festival & 63.9 & 8.2 & 4.9 & 16.4 & 6.6 \\
\hline Belgrade Beer Fest & 44.3 & 9.8 & 14.8 & 26.2 & 4.9 \\
\hline $\begin{array}{l}\text { Ethno Tourism Bacon } \\
\text { Fest, Sausage Festival... }\end{array}$ & 55.7 & 21.3 & 8.2 & 13.1 & 1.6 \\
\hline Religious Sites in Serbia & 36.1 & 16.4 & 6.6 & 34.4 & 6.6 \\
\hline Motorcycle Events & 57.4 & 11.5 & 4.9 & 13.1 & 13.1 \\
\hline
\end{tabular}

Source: Research authors

Finally, we also examined the attitudes of the respondents to the tourism in our country according to the degree of their agreement to the statements offered in the survey. Again, the five-degree Linkert Scale was used, 1 meaning 'completely disagree' and 5 'completely agree' with the statements offered, 2 and 4 are nuances of agreeing and disagreeing, whereas 3 meant 'not sure'. The respondents' responses are shown in Table 3.

Table 3. Frequency answers of respondents on a commitment to local tourist attractions in percentages

\begin{tabular}{|c|c|c|c|c|c|}
\hline & 1 & 2 & 3 & 4 & 5 \\
\hline Serbia has unused tourist potential. & 3.3 & I & 3.3 & 36.1 & 57.4 \\
\hline The future of Serbia lies in the development of tourism. & 3.3 & 3.3 & 21.3 & 42.6 & 29.5 \\
\hline Due to the deficit of our own resources, we are forced to urbanise the tourist resources. & 19.7 & 21.3 & 29.5 & 21.3 & 8.2 \\
\hline Concessions are the best way to accelerate the development of tourism. & 18.0 & 16.4 & 47.5 & 13.1 & 4.9 \\
\hline $\begin{array}{l}\text { The development of tourism in Serbia should be left to foreigners because we do not know } \\
\text { how to deal with it. }\end{array}$ & 42.6 & 23,0 & 16.4 & 9.8 & 8.2 \\
\hline The most important tourist objects should be government-owned. & 19.7 & 19.7 & 18,0 & 29.5 & 13.1 \\
\hline Shoul & 29.5 & 16.4 & 23,0 & 23,0 & 8.2 \\
\hline system of standards, regulations, but also into the & 26.2 & 9.8 & 19.7 & 27.9 & 16.4 \\
\hline $\begin{array}{l}\text { Russia is the best example of tourism development because it has both tourists and } \\
\text { investors at its disposal. }\end{array}$ & 37.7 & 9.8 & 29.5 & 9.8 & 13.1 \\
\hline $\begin{array}{l}\text { All tourist resources should remain government-owned, even if the tourism does not } \\
\text { develop. }\end{array}$ & 45.9 & 24.6 & 19.7 & 4.9 & 4.9 \\
\hline $\begin{array}{l}\text { Regardless of the political situation, the tourist offers of Serbia and Republika Srpska } \\
\text { should be consolidated. }\end{array}$ & 26.2 & 11.5 & 34.4 & 14.8 & 13.1 \\
\hline
\end{tabular}
Source: Research authors

\section{Research Results}

\subsection{Analysis of variance (ANOVA)}

Through One-Factor Analysis of Variance (ANOVA) we examined the differences among the respondents when it 
comes to their habits concerning their vacation and depending on their employment status (Kamenov and others 2006).

Thus, it is shown that the respondents differ from one another with respect to how much money they would be ready to spend on their vacation, $\mathrm{F}(3,182)=2.63, \mathrm{p}<.05$; it is also shown that the pupils/students were ready to spend one monthly income on their vacation, the employed and the unemployed stated they would spend two or three monthly incomes on their vacation, whereas the pensioners stated they would be ready to spend three or four monthly incomes on their vacation.

Then, there were some statistically significant differences among the respondents concerning the country where they would like to spend their vacation, $F(3,182)=6.49, \mathrm{p}<.01$, and it is shown that the employed would usually choose to spend their vacation in Montenegro or Turkey, the unemployed stated they would choose Egypt, the pupils/students stated they would like to spend their vacation in some other country that was not offered as an option in the survey, whereas the pensioners would much rather choose Egypt or Tunisia.

Also, statistically significant differences among the respondents occur concerning the number of days spent on their vacation, $\mathrm{F}(3,182)=5.19, \mathrm{p}<.01$ - the employed stated they would spend their vacation in 10 -15-day periods, pupils/students stated they usually spent 15 days on their vacation, and pensioners stated that they decided about the number of days spent on vacation on their own.

Finally, the respondents also differ from one another significantly concerning the type of accommodation they choose on their vacation, $\mathrm{F}(3,182)=5.46, \mathrm{p}<.01$, and therefore it is shown that the employed would choose an apartment or a room in private accommodation, the unemployed would choose an apartment in private accommodation or the all inclusive option, pupils/students would choose some other option that was not offered as an option in the survey, whereas the pensioners stated they would choose a studio apartment or an apartment in private accommodation.

According to the reviewed results, it can be concluded that the initial hypothesis is confirmed by this analysis, i.e, it is shown that the respondents' habits concerning spending their vacation, differ from each other on the basis of their employment status. The greatest statistically significant differences among respondents are found in the answers concerning the country where the respondents would like to spend their vacation, whereas the smallest ones are found in the answers concerning the amount of money the respondents were ready to set aside for their vacation; this shows that the employment status has the weakest influence on the amount of money the respondents would set aside for their vacation; therefore, in future studies, it should be ascertained which factors influence this variable. On the other hand, we think that those variables, according to which there are statistically significant differences among the respondents, should be included in the next research projects, together with other independent variables related to the respondents' habits concerning their vacation, because this aspect of life is connected with the employment status of the respondents (Hunziher and Krapf, 1942).

With the same type of analysis, we examined if the respondents could be differed from each other as to how interested they are in certain tourist events in our country, depending on the number of their household members.

Thus, it is shown that there are statistically significant differences among the respondents when it comes to their interest in mountain tourism in our country, $\mathrm{F}(5,182)=3.63, \mathrm{p}<.01$; the respondent living alone stated they did not know or that they were pretty interested in mountain tourism, the respondents living in 2-4-member households stated they were not interested or they could not say how interested they were, whereas the respondents in remaining groups stated they were not certain in their level of interest in this form of tourism.

Furthermore, the respondents significantly differ from each other in the level of interest in lake tourism in our country, $\mathrm{F}(5,182)=6.63, \mathrm{p}<.01$; the respondents living alone and the respondents living in 6 -member households stated that they could not say how interested they were or that they were pretty interested, the respondents living in 4-member households stated they were completely or partially interested, whereas the respondents in remaining groups stated they were partially interested or completely uninterested in this form of tourism.

Also, statistically significant differences among respondents are found in the answers concerning their level of interest in spa tourism in our country, $\mathrm{F}(5,182)=10.37, \mathrm{p}<.01$; the respondents living $\mathrm{i}$ one-member households and those living in six-member households stated they could not give their assessment concerning the level of their interest in spa tourism or that they were partially interested, the respondents living in two- or five- member households stated they were mostly uninterested or that they could not give their assessment, whereas the respondents in remaining groups stated they were completely uninterested, and some of them stated they were partially uninterested.

Statistically significant differences among respondents are also found in their answers concerning congress 
tourism, depending on the number of household members $\mathrm{F}(5,182)=17.60, \mathrm{p}<.01$. The results show that the respondents living alone stated they could not say how interested they were or that they were partially interested in this form of tourism, the respondents living in 2-4-member households mostly stated they were completely uninterested and a small number of them stated they were partially uninterested, whereas the respondents living in 5- and 6-member households stated they were partially uninterested.

When it comes to farm tourism, there are also statistically significant differences among respondents $\mathrm{F}(5$, $182)=4.84, \mathrm{p}<.01$; the respondents living alone stated that they were not sure as well as they were partially interested in this form of tourism, the respondents living in two-member and six-member households stated they were mostly uninterested, the respondents living in three-member households mostly stated they were completely uninterested and a small number of them stated they were partially uninterested, whereas the other respondents stated they could not assess the level of their interest in this form of tourism.

Then, there are statistically significant differences among the respondents concerning the level of interest in Exit Festival $F(5,182)=4.78, p<.01$; the respondents living in one- or six-member households stated they could not say how interested they were in Exit Festival, whereas the respondents in other categories stated they were completely or partially uninterested in this event.

Furthermore, there are statistically significant differences among the respondents concerning the religious tourism in Serbia 182)=3.61, $\mathrm{p}<.01$; the respondents living alone mostly showed a neutral attitude toward this form of tourism, the respondents living in 2-5-member households stated either that they were not interested or that they could not say how interested they were, whereas the respondents living in six-member households stated they were mostly or completely interested in this form of tourism.

Finally, there are statistically significant differences among the respondents concerning their interest in motorcycle events $\mathrm{F}(5,182)=7.63, \mathrm{p}<.01$; the respondents living alone stated they could not assess the level of their interest or they were partially interested in this form of tourism, the respondents living in three- and six-member households stated they were partially uninterested or they could not assess the level of their interest, whereas the respondents living in five-member households stated they were completely uninterested in this form of tourism.

Thus, using the above-mentioned variables, it is shown that the initial hypothesis of our study is confirmed, i.e, that they are statistically significant differences among the respondents concerning the level of their interest in certain forms of tourism in our country depending on the size of their households.

The greatest statistically significant differences among respondents are found in the answers concerning congress tourism within which we can see that the largest number of interested respondents are the ones living alone, whereas the smallest ones are found in the answers concerning mountain tourism and religious tourism in Serbia.

Furthermore, the respondents living alone mostly stated they were interested in various forms of tourism, whereas the respondents in other categories mostly stated they were uninterested or they could not assess the level of their interest in various forms of tourism. These results could be coming from the fact that the respondents living alone still have not formed a family, therefore they do not have that kind of responsibilities, thus, they have time to be interested in various forms of tourism, as opposed to the respondents in other categories.

In general, according to these results, we can say that the number of the household members has a significant influence on the respondents' interest in various forms of tourism; but, it would also be useful, for future studies, if additional variables are examined. For instance, who the household members are, since it is assumed they travel with the respondents'; thus, the connection between these variables would be identified better.

\subsection{Chi-square Analysis}

Through Chi-square analysis, we examined to what extent the respondents differ from each other with respect to their agreement with the statements concerning tourism in our country, depending on the number of household members who earn income. This analysis shows statistically significant differences among the respondents, and Table 1 shows the values of Chi-square for each statement. Then, the charts will show the frequencies of the respondents' responses concerning each statement depending on the respondents' level of education.

Thus, concerning the first statement, 'Serbia has unused tourist potential' $\mathrm{x}^{2}(9,183)=69.543, p<01$, it is shown that the respondents living in household with one, two or three incomes stated they partially or completely agreed with the statement, whereas the respondents living in households with four incomes stated they completely agreed. 
Table 4. Hi-sized squares for each and every allegation of respondents

\begin{tabular}{|c|c|c|}
\hline & $\begin{array}{l}\text { The number of household } \\
\text { members who earn income }\end{array}$ & $\begin{array}{l}\text { Statistical } \\
\text { significance }\end{array}$ \\
\hline Serbia has unused tourist potential & $x^{2}(9,183)=69.543$ & $p<.01$ \\
\hline The future of Serbia lies in the development of tourism & $x^{2}(9,183)=27.632$ & $p<.01$ \\
\hline $\begin{array}{l}\text { Due to the deficit of our own resources, we are forced to privatize the } \\
\text { tourist resources }\end{array}$ & $\mathrm{x}^{2}(9,183)=55.089$ & $p<.01$ \\
\hline Concessions are the best way to accelerate the development of tourism & $\mathrm{x}^{2}(9,183)=24.579$ & $p<.05$ \\
\hline $\begin{array}{l}\text { The development of tourism in Serbia should be left to foreigners } \\
\text { because we do not know how to deal with it. }\end{array}$ & $\mathrm{x}^{2}(9,183)=25.662$ & $p<.05$ \\
\hline The most important tourist objects should be government-owned. & $x^{2}(9,183)=39.277$ & $p<.01$. \\
\hline $\begin{array}{l}\text { Should there come to privatization, the buyers should be chosen from } \\
\text { friendly countries. }\end{array}$ & $x^{2}(9,183)=24.061$ & $p<.05$ \\
\hline $\begin{array}{l}\text { The tourist system should fit into a system of standards, regulations, but } \\
\text { also into the system of ownership of EU partners. }\end{array}$ & $x^{2}(9,183)=24.210$ & $p<.01$. \\
\hline $\begin{array}{l}\text { Russia is the best example of tourism development because it has both } \\
\text { tourists and investors at its disposal. }\end{array}$ & $x^{2}(9,183)=37.560$ & $p<.01$. \\
\hline $\begin{array}{l}\text { All tourist resources should remain government-owned, even if the } \\
\text { tourism does not develop. }\end{array}$ & $x^{2}(9,183)=26.264$ & $p<.05$ \\
\hline $\begin{array}{l}\text { Regardless of the political situation, the tourist offers of Serbia and } \\
\text { Republika Srpska should be consolidated. }\end{array}$ & $\mathrm{x}^{2}(9,183)=48.271$ & $p<.01$. \\
\hline
\end{tabular}

.

Source: Research authors

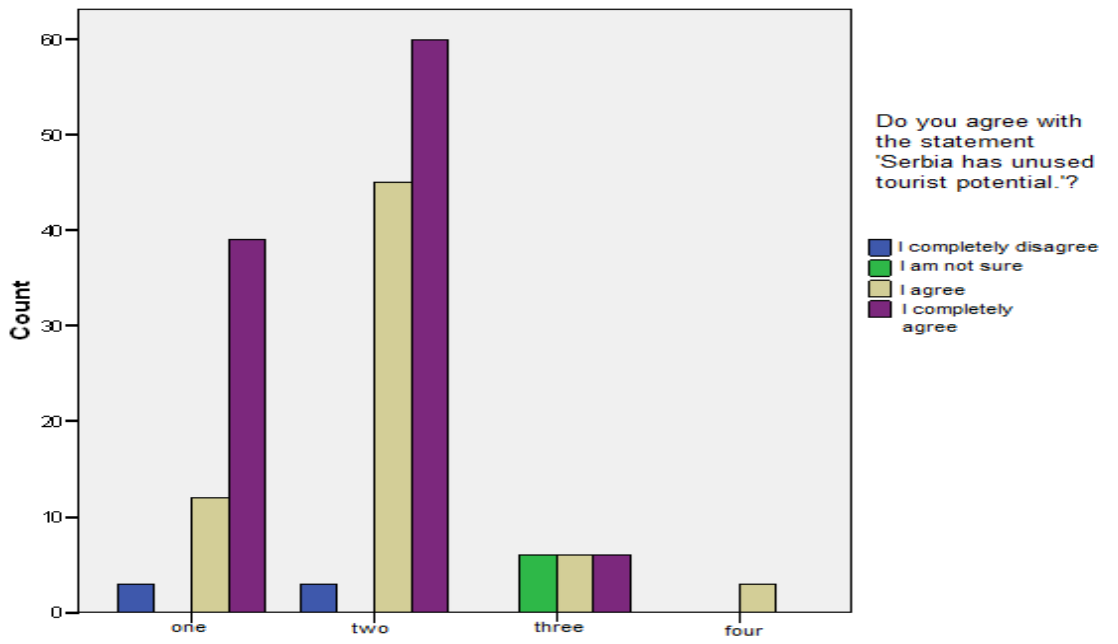

The number of household members who earn income

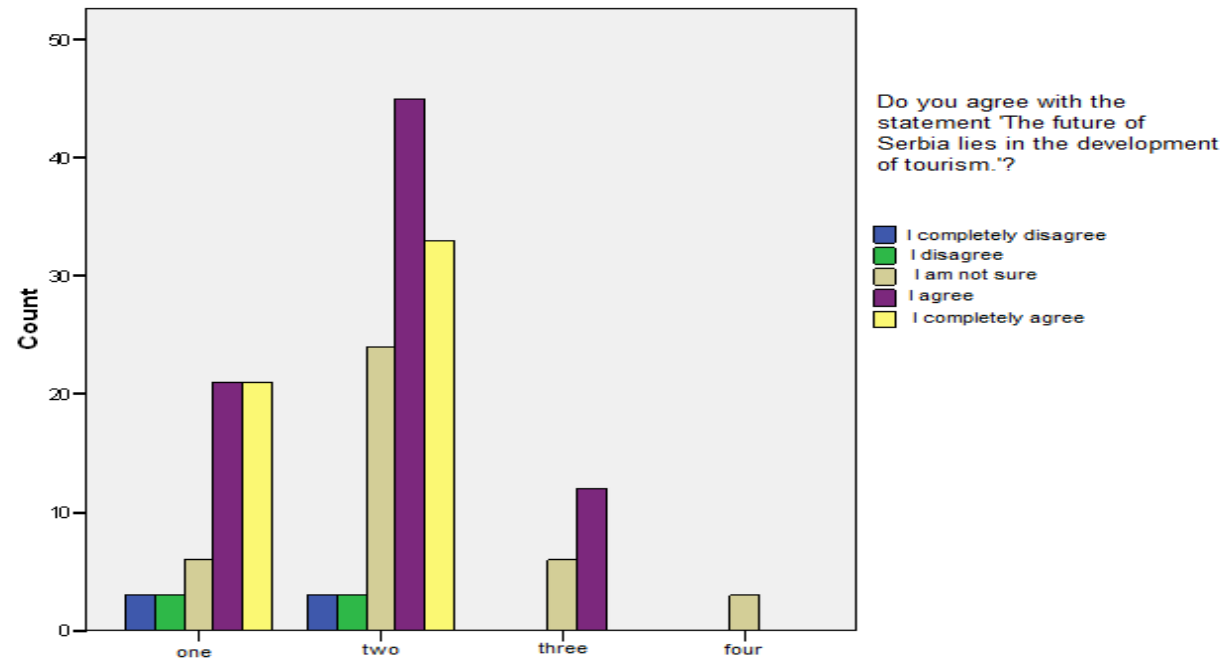

The number of household members who earn income 
When it comes to the statement 'The future of Serbia lies in the development of tourism', it is shown that the respondents living in households with one or two incomes stated they partially and completely agreed with the statement, the respondents living in households with three incomes stated they either partially agreed or were not sure, whereas the respondents earning income stated that they were not sure of the level of their agreement with the statement.

Concerning the next statement, 'Due to the deficit of our own resources, we are forced to privatize the tourist resources', the results of Chi-square analysis show that the respondents living in households with one income almost equally agreed and disagreed with this statement; the respondents living in households with two incomes mostly stated they were not sure of the level of their agreement with the statement, with a small number of respondents that stated they did not agree with the statement; the respondents living in households with four incomes stated they were not sure of the level of their agreement with the statement.

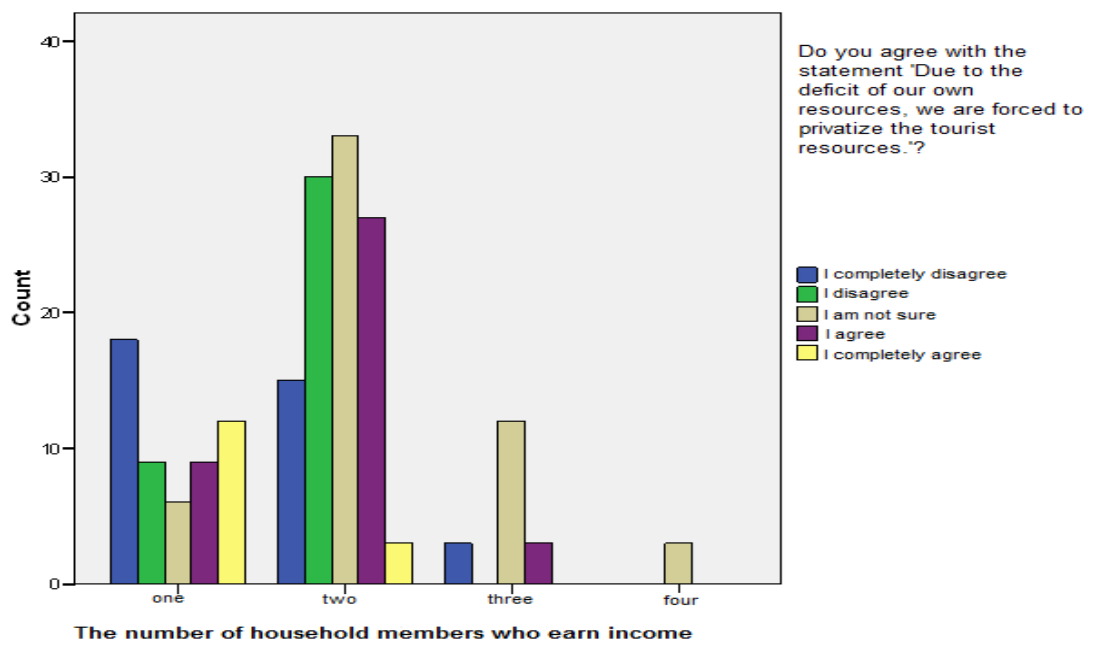

Furthermore, concerning the statement 'Concessions are the best way to accelerate the development of tourism', the results show that the respondents living in households with one, two or three incomes stated they did not have an opinion about it, and a small number of respondents stated they did not agree with the statement, whereas the respondents living in households with four incomes stated they did not have an opinion about the statement in question.

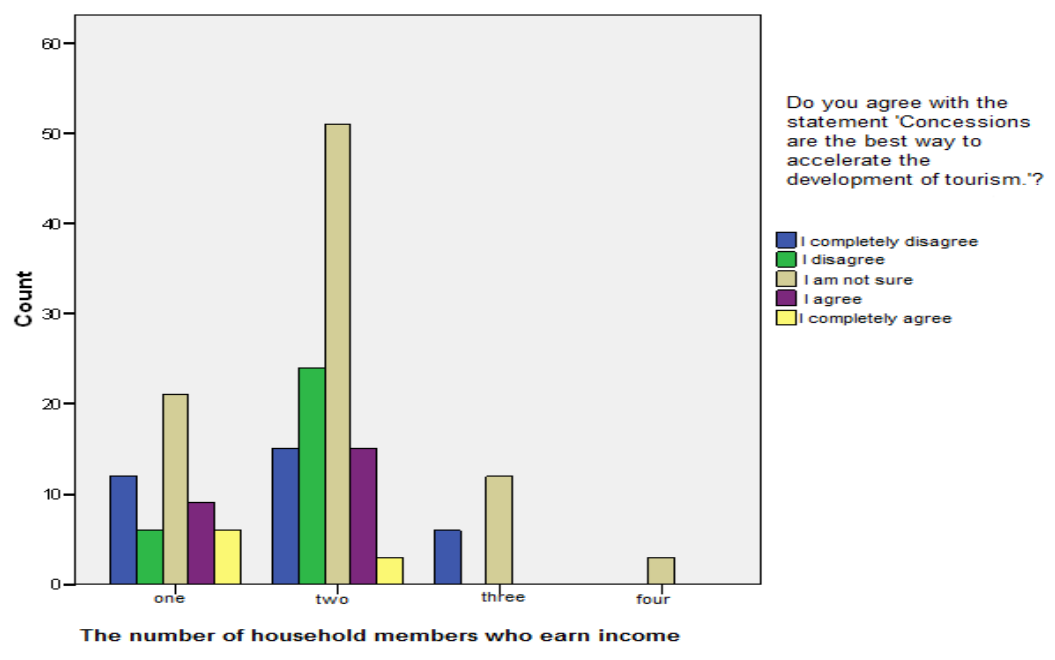

Then, when it comes to the statement 'The development of tourism in Serbia should be left to foreigners because we do not know how to deal with it.', it is shown that the respondents living in households with one or two incomes stated they mostly disagreed and a small number of them stated they did not have an opinion about it; the respondents living in households with three incomes stated they were not sure of the level of their agreement with 
the statement, whereas the respondents living in households with four incomes stated they disagreed with the statement.

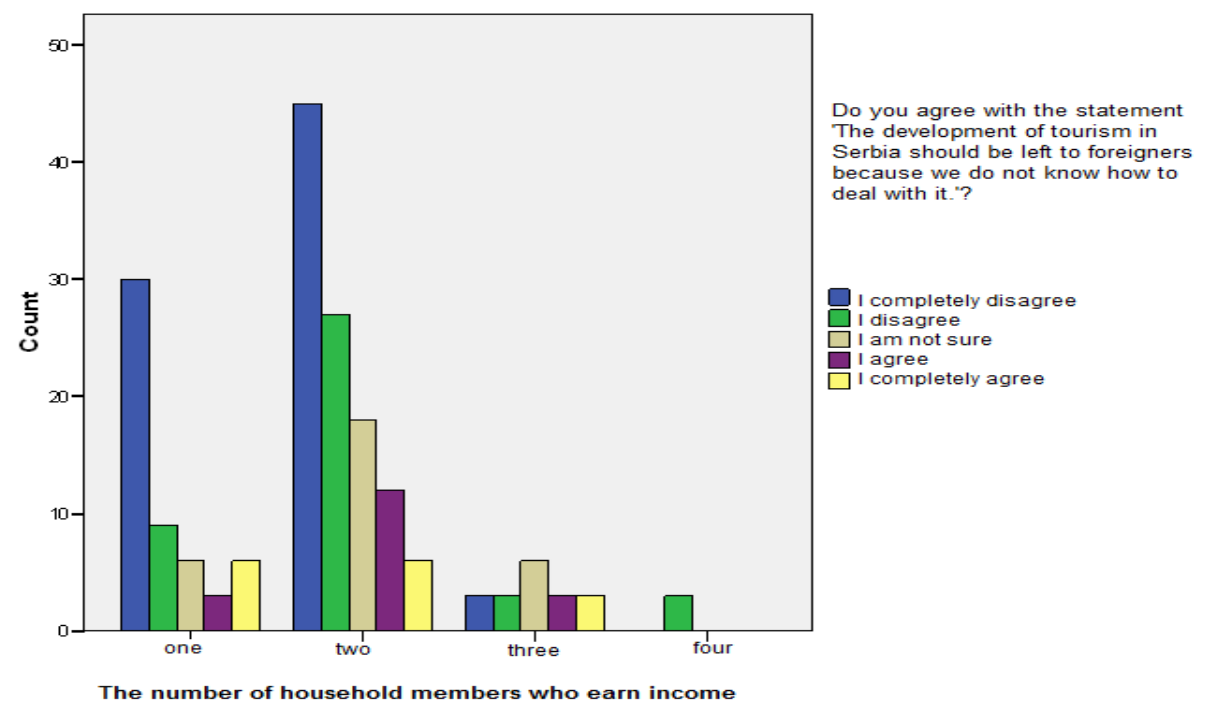

Concerning the statement 'The most important tourist objects should be government-owned', there are also statistically significant differences among the respondents - the respondents living in households with one or two incomes showed almost equal level of agreement and disagreement with the statement; the respondents living in households with three incomes stated they were not sure of the level of their agreement with the statement, whereas the respondents living in households with four incomes stated they agreed with the statement.

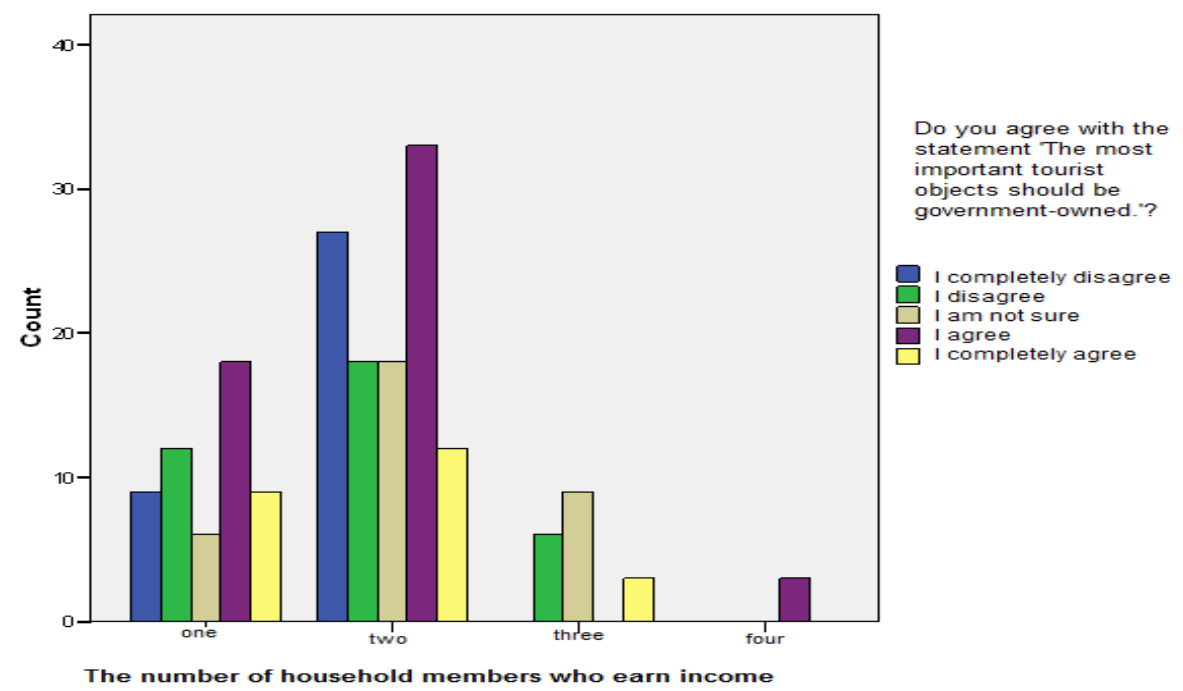

Then, when it comes to the statement 'Should there come to privatization, the buyers should be chosen from friendly countries', there are also statistically significant differences among the respondents - the highest level of agreement with the statement can be found with the respondents living in households with one or two incomes (they showed an equal level of agreement and disagreement with the statement); the respondents living in households with three incomes showed that they disagreed as well as they were not sure of the level of agreement with the statement, whereas the respondents living in households with four incomes stated they agreed with this statement. 


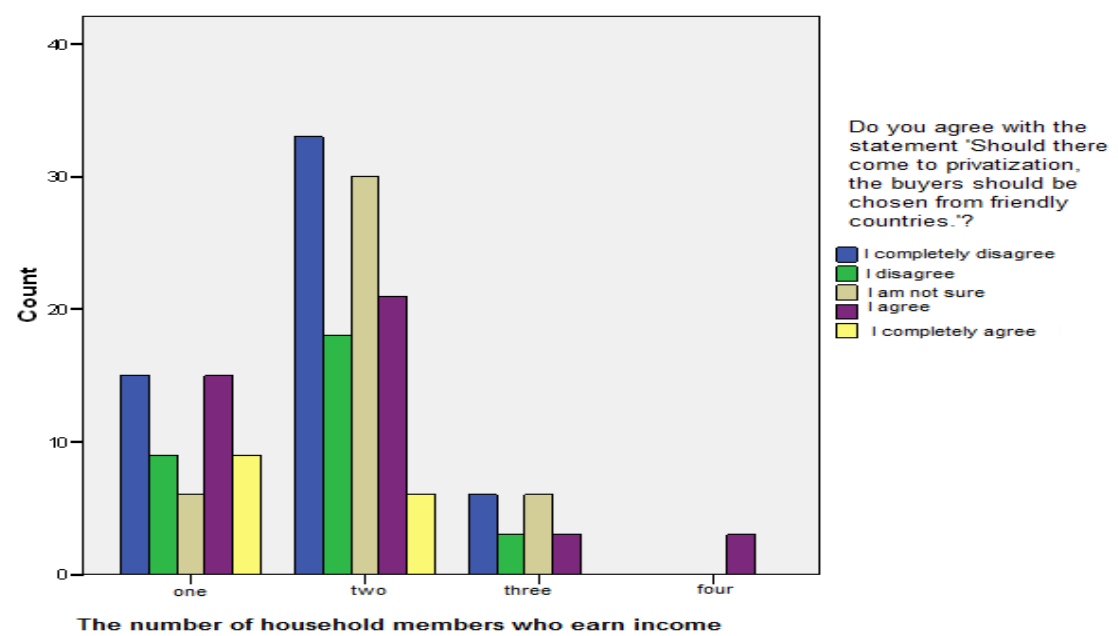

Furthermore, concerning the statement 'The tourist system should fit into a system of standards, regulations, but also into the system of ownership of EU partners', the analysis shows that the respondents living in households with one income stated they mostly agreed, and a small number of them stated they disagreed; the respondents living in households with two incomes gave the same answers, whereas the respondents living in households with three or four incomes stated they were not sure of the level of their agreement with the statement

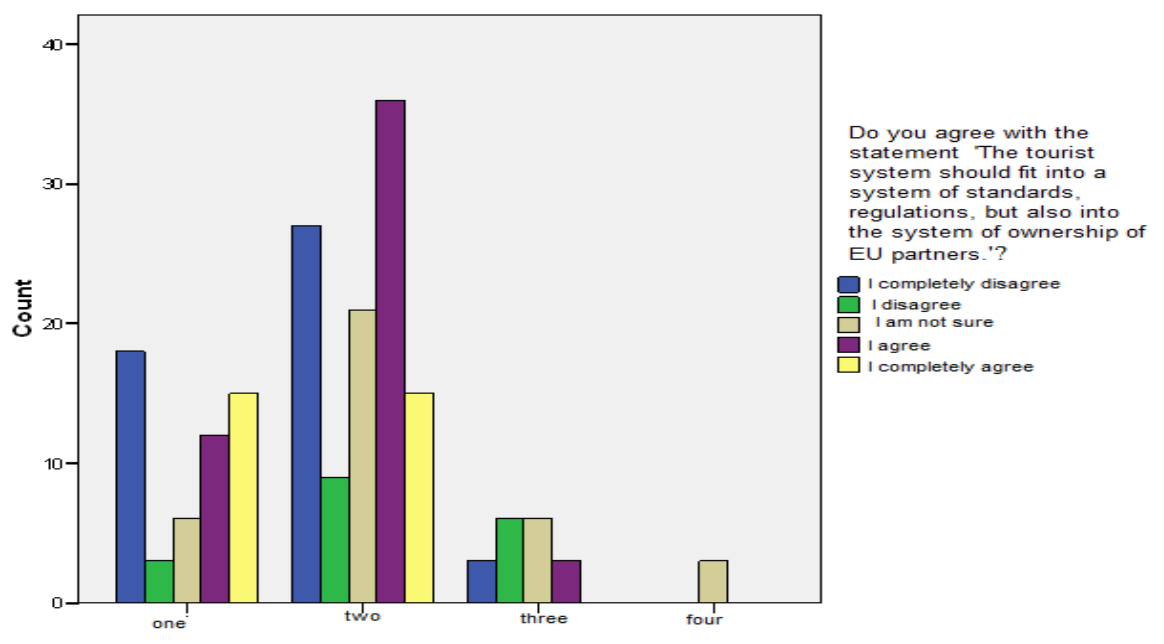

The number of household members who earn income

Furthermore, concerning the statement 'Russia is the best example of tourism development because it has both tourists and investors at its disposal', the analysis shows that the respondents living in households with one income stated they were not sure, and a small number of them stated they disagreed; the respondents living in households with two incomes mostly stated they disagreed with the statement, whereas the respondents in other categories mostly stated they were not sure of the level of their agreement with the statement.

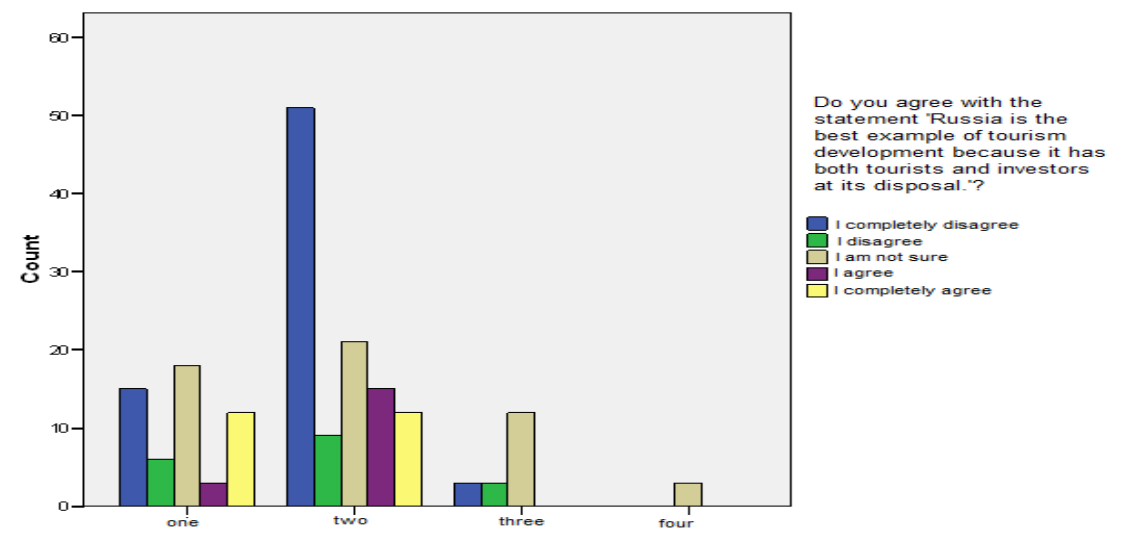


Then, concerning the statement 'All tourist resources should remain government-owned, even if the tourism does not develop', there are also statistically significant differences among the respondents $\mathrm{x}^{2}(9,183)=26.264 p<.05$ the respondents living in households with one, two or three incomes stated they disagreed with this statement or they were not sure of the level of their agreement, whereas the respondents living in households with four incomes stated they disagreed.

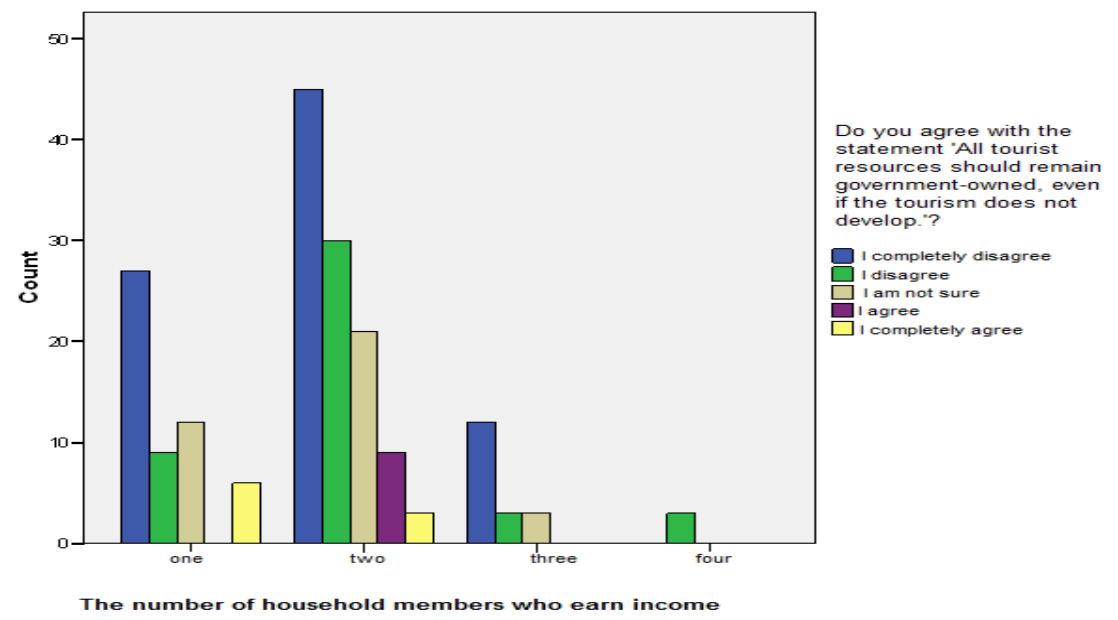

Finally, when it comes to the statement regardless of the political situation, the tourist offers of Serbia and Serbian Republic (a separate entity within the state of Bosnia and Herzegovina), be brought together into a unique tourist offer, we also found statistically significant differences among the respondents. The respondents living in households with one or two incomes stated, in equal amount, that they disagreed and that they were not sure of the level of their agreement; the respondents living in households with three incomes stated they were not sure of the level of their agreement with the statement, whereas the respondents living in households with four incomes stated they agreed with the statement.

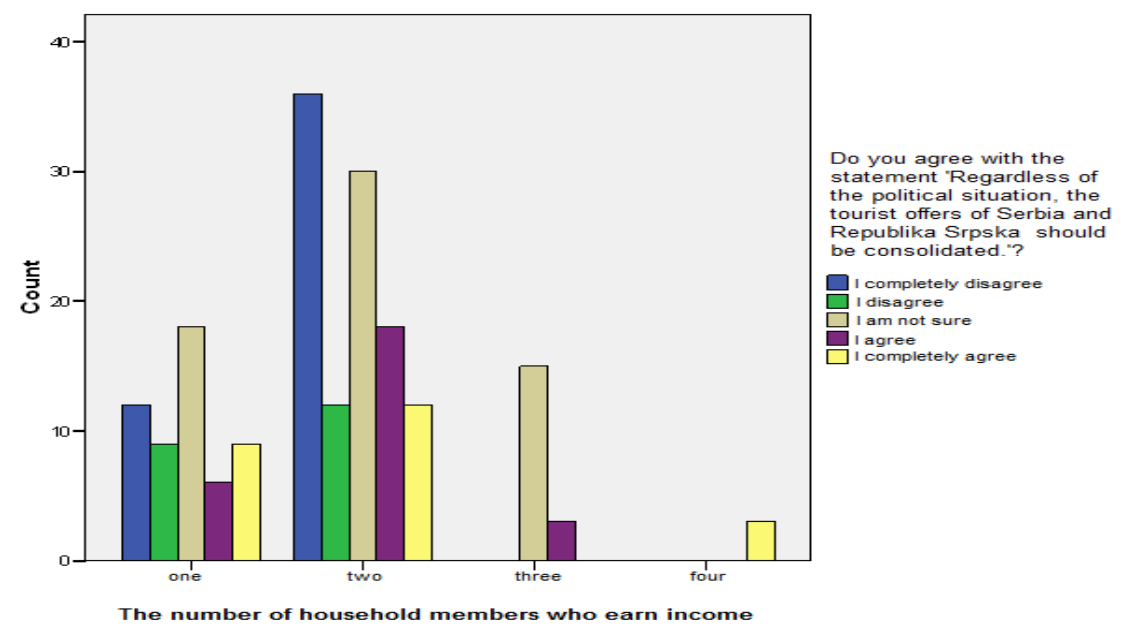

Based on the results of the analysis, it can be concluded that our initial hypothesis is confirmed, that is, there are statistically significant differences among the respondents with respect to the level of their agreement with the given statements depending on the number of household members who earn income. The greatest statistically significant differences among the respondents can be found in the statements: 'Serbia has unused tourist potential', 'Due to the deficit of our own resources, we are forced to privatize the tourist resources'; the highest level of agreement with these statements is found with the respondents living in households with lower number of incomes.

If we observe the respondents' level of agreement with certain statements, we can conclude that the respondents mostly had neutral attitudes to them or they equally agreed and disagreed with them; this can indirectly show that the respondents' attitudes toward these statements probably depend on other variables. Also, the respondents all agree that the tourism in Serbia should be improved; to that end, they are more prone to the EU and its regulations, rather then Russia. Thus, other dependent variables should be included in the future studies - the variables related to those dependent variables which show the greatest differences among the respondents in order to ascertain the connection between these dependent variables and the independent variable used in this study. 


\subsection{Correlation Analysis}

Through Correlation analysis we examined the connection between certain independent and dependent variables, i.e, the variables which were used for examining how important the respondents found certain elements and their habits concerning travel. The correlations are shown in the table.

Table 5. Correlation analysis

\begin{tabular}{|c|c|c|c|}
\hline & $\begin{array}{l}\text { Employment } \\
\text { status }\end{array}$ & $\begin{array}{c}\text { The number of } \\
\text { household members }\end{array}$ & $\begin{array}{c}\text { The number of members } \\
\text { who earn income }\end{array}$ \\
\hline The amount of money for vacation & $.146 *$ & / & $-.195 * *$ \\
\hline The way of vacation financing & / & / & 1 \\
\hline The most preferable place for vacation & / & $-.205 * *$ & / \\
\hline The most preferable country for vacation & $240 * *$ & $-.310 * *$ & / \\
\hline The length of stay on vacation & $215^{* *}$ & 1 & / \\
\hline The type of transportation & l & I & $.327 * *$ \\
\hline The type of accommodation & $.171 *$ & $.237 * *$ & / \\
\hline The importance of having a mini bar & / & / & / \\
\hline The importance of having a safe & / & / & / \\
\hline The importance of having a car park & / & $.147 *$ & / \\
\hline The importance of having a pool & / & / & / \\
\hline The importance of having an aqua park & $.218 * *$ & / & / \\
\hline The importance of having sport facilities & $.149 *$ & / & / \\
\hline The importance of medical services & I & $.268 * *$ & I \\
\hline The importance of spa facilities & / & / & / \\
\hline The importance of having a playground & / & $.524 * *$ & $-.245 * *$ \\
\hline Th importance of having a kitchen / kitchenette & / & $-.153 *$ & $.248 * *$ \\
\hline The importance of having a flat screen TV & / & / & / \\
\hline The importance of having a jacuzzi & / & / & \\
\hline The importance of having air-conditioning & / & $.151 *$ & / \\
\hline $\begin{array}{l}\text { The importance of having a view of tourist } \\
\text { attractions (beach...) }\end{array}$ & I & / & / \\
\hline The importance of having a terrace & I & $.190 * *$ & / \\
\hline The importance of having a washing machine & I & I & I \\
\hline The importance of sound insulation & / & / & / \\
\hline The importance of having Wi-Fi & $-.215 * *$ & / & / \\
\hline The importance of fitness centre & 1 & / & / \\
\hline The importance of having a non smoking room & $-.164 *$ & $.198 * *$ & $.226 * *$ \\
\hline The importance of having a family room & l & $.517 * *$ & / \\
\hline The importance of allowing pets & $-.172 *$ & / & $-.179 *$ \\
\hline $\begin{array}{l}\text { The importance of having the premises adapted } \\
\text { for persons with disabilities }\end{array}$ & I & I & / \\
\hline $\begin{array}{l}\text { The importance of having a disco / club for } \\
\text { children }\end{array}$ & / & $.438 * *$ & / \\
\hline $\begin{array}{l}\text { The importance of other services (hairdresser, } \\
\text { masseur...) }\end{array}$ & $.175^{*}$ & / & I \\
\hline The importance of the distance from the tourist & / & $.264 * *$ & / \\
\hline
\end{tabular}

Based on the results of the analysis, it can be concluded that our initial hypothesis is confirmed, that is, it is established that there is a connection between independent and dependent variables. The highest degree of correlation between variables was found between the number of household members and the importance of having a playground, a family room and a disco/club for children on vacation, and, since all the correlations are connected, these results show that the higher number of household members is, the higher is the level of importance of the above mentioned elements (Sakotic-Kurbalia, 2013).

Furthermore, the only variable, statistically significant and connected with all three dependent variables, is the level of importance of having a non-smoking room, and according to the correlations obtained, it is concluded that the employed respondents, the respondents living in households with higher number of incomes and households with higher number of members in general, all stated higher level of importance of this element.

Then, if we only observe with which independent variables there is the highest number of correlations, we can see that the highest number of correlations can be found with the number of household members, then with the respondents' employment status, and finally with the number of household members who earn income. These results show that those dependent variables with the highest degree of correlation with, again, the independent variable with the most correlations with dependent variables, should be included in future studies; this tells us that the number household members probably significantly influences if the respondents would choose the offers that 
do not have these elements. Naturally, the future studies should be directed to the inclusion of new dependent variables together with these independent variables in order to better ascertain with which elements of tourist offers there are statistically significant correlations.

\subsection{Linear Regression}

Multiple regression was used to examine if two groups of dependent variables could be predicted based on the respondents' employment status, on the number of the respondents' household members and on the number of members earning income in the respondents' households. First, we examined if the respondents' vacation habits could be predicted, and then if using this linear combination of predictor variables could predict the level of importance of certain elements of tourist accommodation (Krippendorf, 1986).

Firstly, it is shown that is possible to predict, with statistical significance, the amount of money/monthly incomes the respondents are ready to set aside for their vacation $R^{2}=.05, F(3,182)=3.604 p<.05$; and the number of members earning income stands out as the individually significant predictor variable - $.16, t=-2.092, p<.05$, which means that the higher the number of household members is, the smaller number of incomes the respondents are ready to set aside.

Then, the place the respondent choose for their vacation can also be predicted using this linear combination of predictor variables $\mathrm{R} 2=.04, F(3,182)=2.664, p<.05$, and the number of household members stands out as the individually significant predictor variable $-.21, t=-2.610, p<.01$, which means that the respondents living in households with a smaller number of members spend their holiday at the seaside as opposed to other respondents.

When it comes to the respondents' choice of destination for their vacation, again, this combination of predictor variables showed itself as statistically significant $R^{2}=.13, F(3,182)=8.905, p<.01$. The respondents' employment status stands out as the significant predictor variable $=.17, t=2.436, p<.01$, as well as the number of household members $-.29, t=-3.849, p<.01$, which means that the employed respondents and those living in households with a smaller number of members rather choose Greece as their vacation destination.

Furthermore, the length of stay on vacation can also be predicted using the same predictor variables, $R^{2}=.05$ $F(3,182)=3.304 p<.05$. The respondents' employment status stands out as as the only significant predictor variable $=.22, t=3.010 p<.01$, i.e, the unemployed respondents spend more time on vacation.

It is shown, with the same analysis, that it is possible to predict, with statistical significance, the way the respondents get to their vacation destination $R^{2}=.16, F(3,182)=11.911, p<.01$, whereas the number of household members $-.25, t=-3.432, p<.01$ and the number of members earning income $.40, t=5.566, p<.01$ stand out as the individually significant predictor variables. These results show that the smaller number of household members is and the larger number of household members earning income is, the less the respondents use their own transportation.

Then, concerning the type of accommodation, this combination of predictor variables also showed itself as significant, $R^{2}=.11, F(3,182)=7.731, p<.01$; the respondents' employment status $=.24, t=-3.351 p<.01$ and the number of household members $=.31, t=4.095 . p<.01$ stand out as the individually significant predictor variables, which means that mostly the unemployed respondents living in households with a larger number of members choose hotel accommodation or apartment accommodation.

Based on the results concerning the first group of dependent variables, we can say that almost all of them could be predicted using this combination of predictor variables. The highest degree of prediction occurred with respect to predicting the way the respondents get to their vacation destination/the type of transportation, and the number of household members stands out as the most frequent individually significant predictor variable (Armenian, 2014).

In the second part of the regression analysis, we examined if the level of importance the respondents give to certain elements of their vacation can be predicted depending on this linear combination of predictor variables.

The first element whose level of importance can be predicted with statistical significance is the importance of having a car park $R^{2}=.05 F(3,182)=5.186, p<.01$. Only the number of household members $=.22, t=2.872 p<.05$ stands out as the individually significant predictor variable, which means that this element is more important to the respondents living in household with a larger number of members.

Furthermore, it is shown that, with this combination of predictor variables, it is possible to predict the level of importance the respondents give to having an aqua park $R^{2}=.08 F(3,182)=5.313, p<.01$, and the respondents' employment status $.25 t=3.426, p<.01$ and the number of household members $.19, t=2.449 p<.01$ stand out as the individually significant predictor variables.

Also, it is shown that it is possible to predict the level of importance the respondents give to medical services on 
their vacation $R^{2}=.10 F(3,182)=6.698, p<.01$; the respondents' employment status $.16 t=2.256, p<.05$ as well as the number of household members $.33 t=4,241, p<.01$ stand out as the individually significant predictor variables. The obtained values of beta weights tell us that the unemployed respondents and the respondents living in household with a larger number of members give higher level of importance to having medical services at disposal on their vacation.

Furthermore, the level of importance of having a playground is the next element which can be predicted using this combination of predictor variables $R^{2}=.32 F(3,182)=28.664, p<.01$. The number of household members in general $=.61, t=9.116, p<.01$ and the number of household members earning income $=-.23, t=-3.620 p<.01$ stand out as the individually significant predictor variables; these values of beta weights show that the larger number of household members and the smaller number of household members earning income suggest the higher probability of the respondents deeming this element more important.

A statistically significant prediction is made concerning the level of importance of having a kitchen / kitchenette $R^{2}$ $=.08 F(3,182)=8.742, p<.01$; the respondents' employment status $=-.14, t=-2.016 p<.05$ and the number of household members $=-.22, t=-2.923 p<.01$.are the individually significant predictor variables. Based on obtained values of beta weights we can conclude that this element is more important to the employed respondents and to the respondents living in households with a smaller number of members.

Then, statistically significant differences among the respondents occur when it comes to the level of importance of having a terrace $R^{2}=.05 F(3,182)=3.684, p<.05$, and the number of household members $=.21, t=2.671 p<.01$ stand out as the individually significant predictor variable, which shows that the respondents living in households with a larger number of members give higher level of importance to this element.

Furthermore, the level of importance of Wi-Fi can also be predicted using this linear combination of predictor variables $R^{2}=.05 F(3,182)=3.209, p<.05$. The respondents' employment status $-.22, t=-2.975 p<.01$ stands out as the individually significant predictor variable, and this value of beta weights shows that the employed respondents deem this element important.

The level of importance of having a non-smoking room $R^{2}=.06 F(3,182)=5.229, p<.01$ is the next element to be predicted using with statistical significance - the number of household members earning income $.17, t=2.295$ $p<.05$ stands out as the individually significant predictor variable, which means that the respondents living in households with a larger number of members deem this element more important.

The next element to be predicted using with statistical significance is the level of importance of having family rooms $R^{2}=.29 F(3,182)=25.037, p<.01$. The number of household members $.58, t=8.422 p<.01$ and the number of household members earning income -.18, $t=-2.695 p<.01$ stand out as the individually significant predictor variables. These results show that this element is more important to the respondents living in households with a larger number of members

The level of importance of having pets allowed can be predicted using this combination of predictor variables $R^{2}$ $=.07 F(3,182)=4.789, p<.01$ and the respondents' employment status $-.17, t=-2.352 p<.05$ as well as the number of household members earning income $-.22, t=-2.935 p<.01$, stand out as the individually significant predictor variables.

The level of importance of having a disco / club for children is the next element that can be predicted using with statistical significance $R^{2}=.24 F(3,182)=19.739, p<.01$. The number of household members $.54, t=7.670 p<.01$ and the number of household members earning income $-.22, t=-3.214 p<.01$ are the individually significant predictor variables; these results show that the bigger the number of household members and the smaller number of household members earning income mean that the respondents from these categories deem this element more important.

The level of importance of other accommodation services can also be predicted with statistical significance using these predictor variables $R^{2}=.05 F(3,182)=3.129, p<.05$, and the respondents' employment status $.19, t=2.253$ $p<.01$ is the only individually significant predictor variable, which means that that the unemployed respondents deem these services more important.

Finally, the level of importance of the distance from the tourist attractions is also predicted with statistical significance using this combination of predictor variables $R^{2}=.07 F(3,182)=4.840, p<.01$, and the number of household members .23, $t=2.980, p<.01$ is the only individually significant predictor variable; that means that the respondents living in households with a larger number of members deem this element more important.

And so, it is shown that the values of this group of dependent variables can also be predicted with statistical significance using this linear combination of predictor variables; this confirms the initial hypothesis of this study. 
The elements that showed the highest degree of prediction are: the level of importance of having a playground, family rooms and disco / club for children; particularly interesting is the fact that these elements are more important to the respondents living in households with a larger number of members and with a smaller number of incomes, which suggests that they are family people and that they probably travel with their children. The number of household members does stand out as the most frequent individually significant predictor variable, whereas the other two variables stand out as the significant predictors almost as frequently. For both groups of variables, the number of predictor variables is actually the variable according to which is possible to predict the respondents' habits and how important certain elements are to them; this tells us that these forms of travel are very much connected with this independent variable.

The fact is known in theory and in practice, that the factors of demand driving factors of tourism development to generate a complete development of tourism with all its effects and impacts, on the other hand, the fact that some authors, all of the impacts of tourism can be sorted into seven general categories (Glenn, 2001, page 3): Economic, Environmental, Social and cultural, Crowding and congestion, Services, Taxes and Community attitude, confirm how important socio-economic characteristics of the population to the tourist demand and thus for overall development of tourism.

\section{Conclusion}

Based on the obtained data, it can be concluded that, through statistical analyses, the initial hypotheses of our study are confirmed, i.e, that there are statistical correlations between the dependent and independent variables.

Using One-Factor Analysis of Variance, it was initially shown that there were statistically significant differences among the respondents with respect to their vacation habits depending on their employment status. Namely, the primary finding of this study is that the greatest differences among the respondents, depending on this variable, occur with respect to the respondents' choice of destination, which is expected, since the way the respondents spend their vacation probably depends on their employment status, that is, whether they choose more or less exclusive destination. The same analysis shows that there are statistically significant differences among the respondents concerning their interests in various forms of tourism, depending on the number of their household members, and, as it has been said, the respondents living alone mostly stated they were interested in various forms of tourism, as opposed to the respondents from other categories who stated they were less interested in them. These results may come from the fact that the respondents living alone have more time and are more leisure to organise their vacation according to their needs, which allows them to explore various forms of tourism.

When it comes to Chi-square analysis, it has been shown that this segment of the respondents' behaviour can be better understood based on one socio-demographic variable. However, we think that the respondents' attitudes concerning this subject are very much influenced by other factors, such as the general political situation or the respondents' financial status; therefore, we believe that the correlations between these variables should be examined in future studies.

When it comes to Correlation and Regression analyses, they have shown how connected the respondents' habits and the level of importance they give to certain elements are with the independent variables in this study. It is specially emphasized that the respondents living in households with a larger number of members and with a smaller number of members earning income value the child-oriented elements on their vacation more compared to the respondents in other categories. These data could be of strategic importance for all those involved in the design and realization of tourist offer; therefore, if they want to attract people with children, they should definitely include these elements in their offer.

We also believe that the study has its practical and theoretical value because it shows how the respondents' habits, behaviour and perception concerning their vacation are influenced by the socio-demographic variables used in this study. Still, as a suggestion for future studies, we think that, besides the number of household members and the number of household members who earn income, it should be examined with whom the respondents live, who earns income and how big the income is and those values should be correlated with the above dependent variables. Furthermore, we believe that it is necessary to examine with whom the respondents usually spend their vacation, but also how they finance it, because all these results show that there is a significant correlation between the respondents' financial status and that of their household members with their decision about how they will spend their vacation.

However, the limitations of our study lie in the fact that we examined a small number of respondents; therefore, we believe that a larger number of respondents are necessary for additional verification. 


\section{References}

Armenian, T. (2014). The effect of image and overall satisfaction in the consumer loyalty in tourism-primer-Serbia- doctoral thesis, University of Novi Sad, Faculty of Sciences, Novi Sad, Serbia.

Bulent, JSC., Ozer, O., \& Çaliskan, U. (2015). The relationship between local residents' perceptions of tourism and their happiness: a case of Kusadasi, Turkey, (pp. 232-242), available http://www.emeraldinsight.com/toc/tr/70/3 (27.08. 2015), Turkey.

Butrovac, I. (2014). Likert scale, available http://www.scribd.com/doc/210936532/likertova-skalaLikertova-skala\#scribd (25.08.2015). Croatia.

Glenn, K. (2001). The Impacts of Tourism. http://www.seagrant.umn.edu/tourism/pdfs/ImpactsTourism.pdf (14.01.2017), Minnesota, USA.

Grozeva, M. (2016). Some tendences of tourism development in the age of globalization. http://geoproblems.eu/wp-content/uploads/2016/10/2016_12/1_grozeva.pdf (14.01.2017), Bulgaria.

Hunziker, W., \& Krapf, K. (1942). The floor plan of Allgemaine Tourist teaching. Zurich: Polygraphischer Publisher, Switzerland.

Kamenov, Z., Sladovic, B. F., \& Ajdukovic, M. (2006). The development of scale in researching attitudes toward exclusion of children from families and foster care, available,

Krippendorf, J. (1986). Travelling humanity. In the new concept of leisure time and travel. Zagreb: Institute for Tourism Research- SNL. Croatia.

Moreno, L. J. (1978). Who shall survive-Foundations of Cosiometry, group psychoterapy and sociodrama, Beancon House, inc., USA.

Muratovic, L. (2013). Socio-demographic variables as predictors of academic achievement motivation, School vjesnik. Journal of pedagogical and educational issues, 62(2-3), July 2013. Croatia.

Petrovecki, M., \& Bill-Zula, L. (2015). Variables, measurement, data, available, http://mi.medri.hr/assets/P3_Mjerenje\%20i\%20prikupljanje\%20podataka.pdf (27.08.2015). Croatia.

Sakotic-Kurbalija, J. (2013). The connection quality of the marital relationship with sociodemographic variables, Contemporary trends in psychology, 181-182, Novi Sad Faculty of Philosophy, Srebia.

Vujovic, S. (2008). The material basis of tourism, Institute of Agricultural Economics, Belgrade, Serbia.

\section{Copyrights}

Copyright for this article is retained by the author(s), with first publication rights granted to the journal.

This is an open-access article distributed under the terms and conditions of the Creative Commons Attribution license (http://creativecommons.org/licenses/by/4.0/). 